\title{
Algumas considerações sobre o Plano Diretor dos municípios e sua importância no processo de construção da cidadania e da democracia
}

\author{
Miguel Etinger de Araújo Junior ${ }^{1}$
}

\begin{abstract}
Resumo
O processo de urbanização no Brasil, compreendido como o aumento da população das áreas urbanas e conseqüente diminuição da população rural, é um fenômeno que vem se intensificando nas três últimas décadas. Suas causas são várias, bem como as conseqüências para a população como um todo. A ocupação desordenada do espaço urbano acarreta uma série de prejuízos para o meio ambiente e consequentemente para a pessoas que residem em áreas urbanas, exigindo uma efetiva intervenção do Poder Público no sentido de melhorar a ocupação desordenada e planejaras ocupações futuras. Este processo deve se pautar em um planejamento prévio e contar com a participação obrigatória da população afetada, de forma a atender o comando constitucional da democracia participativa. O Plano Diretor é um dos elementos aptos a promover essa melhora do espaço urbano. Trata-se de uma lei municipal com previsão constitucional que veio a ser regulamentada pelo Estatuto da Cidade (Lei no 10.257/2001) que traçou seus objetivos e diretrizes. O presente trabalho pretende abordar os aspectos mais relevantes em relação ao Plano Diretor, em especial sua contribuição à solidificação da democracia e da cidadania a partir da efetiva participação popular no seu processo de elaboração.
\end{abstract}

Palavras-Chave: Plano Diretor; Estatuto da Cidade; Democracia; Cidadania; Participação popular; Urbanismo.

\section{Plano Diretor}

\subsection{Conceito}

Num primeiro momento pode-se definir o Plano Diretor como uma lei municipal, cuja elaboração está prevista na Constituição Federal de 1988, em seu artigo 182, § 1ํ, como sendo o instrumento básico da política de desenvolvimento e de expansão urbana.

Câmara² observa que a idéia do Plano Diretor é antiga, anterior ao Estatuto da Cidade, que veio a lhe dar contornos jurídicos mais elaborados.

Professor de Direto Administrativo e Teoria Geral do Processo na Universidade Estadual de Londrina.

CÂMARA, Jacinto Arruda. Plano diretor. In: DALLARI, Adilson Abreu; FERRAZ, Sérgio. Estatuto da Cidade: comentários à lei federal 10.257/2001. São Paulo: Malheiros, 2003. p. 308 
É interessante observar que o Plano Diretor, no Brasil da década de 60 e 70, sempre foi concebido por arquitetos e urbanistas, que elaboravam normas sob uma ótica técnica individualizada, não contextualizada com o conjunto de fatores que influenciam e condicionam a ocupação e utilização dos espaços urbanos.

Silva $^{3}$, em obra anterior ao Estatuto da Cidade, aponta quatro fases evolutivas do Plano Diretor.

A primeira, preocupada com o que chama de "desenho da cidade", associada à idéia de estética urbana. A segunda, relacionada à distribuição das edificações sob a ótica econômica e arquitetônica. Num terceiro momento adota-se a idéia de um plano de desenvolvimento integrado, aplicando-se o conceito de planejamento, que integre vários setores da municipalidade. Uma Quarta etapa surge após a Constituição Federal de 1988 refletindo a idéia mencionada acima, constante do $\S 1$ 10 do art. 182 da Constituição Federal de 1988, voltada para a ordenação do pleno desenvolvimento das funções sociais da cidade e garantia do bem-estar da comunidade local.

Esse processo constitui uma mudança de enfoque, do estático para o dinâmico, passando a compreender a "sistematização do desenvolvimento futuro" em substituição à "sistematização do que já existe" ${ }^{4 "}$.

A base da conceituação, portanto, é a necessidade de lei, de âmbito municipal, para a instituição do Plano Diretor. É uma exigência constitucional (art. 182, § 1ㅇ).

Como é parte integrante de nosso sistema jurídico, a ele deve se adequar e interagir. Está, portanto, sujeito aos princípios gerais instituídos pela Constituição Federal de 1988, devendo seus dispositivos, sob a ótica da normatização dos espaços urbanos, promoverem a dignidade da pessoa humana, a preservação e equilíbrio do meio ambiente etc.

Sob outro aspecto, e buscando traçar as características gerais do Plano Diretor, vale observar que a idéia da função social da propriedade urbana vai ser alcançada se esta propriedade atender às exigências fundamentais de ordenação da cidade previstas no Plano.

SILVA, José Afonso da. Direito urbanístico brasileiro. São Paulo: Malheiros, 1995. p. 87.

SPANTIGATI, Frederico. Manual de derecho urbanistico. Madrid: Editorial Montecorvo, 1973 APUD SILVA, 1995. 


\title{
Algumas considerações sobre o Plano Diretor dos municípios e sua importância no processo de construção da cidadania e da democracia
}

O município é o espaço ideal para o debate sobre as necessidades locais, devendose observar que qualquer deliberação deve estar em sintonia com os princípios regionais e nacionais.

Outra característica importante do Plano Diretor é que sua instituição é obrigatória para a efetiva implementação de diversos institutos jurídicos que o Poder Público pode implementar, no sentido de impor sanções ao proprietário do solo urbano não edificado, subutilizado ou não utilizado.

Uma dessas hipóteses está prevista no artigo 182, § 40 da Constituição Federal que condiciona à prévia inclusão de determinada área no Plano Diretor, para que o Poder Público possa compelir ao adequado aproveitamento do solo urbano, sob pena de haver, sucessivamente: I - parcelamento ou edificação compulsória; II - IPTU progressivo no tempo; III - desapropriação para fins urbanísticos.

Também o Estatuto da Cidade condiciona a aprovação do Plano Diretor para a implementação de diversos institutos como: I - outorga onerosa do direito de construir; II direito de preempção; III - operações urbanas consorciadas; IV - transferência do direito de construir.

Uma outra característica importante observada por Câmara ${ }^{5}$ é sua necessidade de incorporação ao plano plurianual, às diretrizes orçamentárias e ao orçamento anual (artigo 40, § 1으, Lei ํo 10.257/2001).

O Plano Diretor é, portanto, uma diretriz do Poder Público e da própria sociedade. Neste sentido afirma Alaor Caffé Alves, citado por Mukai:

\begin{abstract}
Justamente por estar formalizado como modelo e como pauta, serve perfeitamente como conduta e, portanto, como direito e base de um juízo sobre seu cumprimento. O plano é uma pauta de conduta que cria diretrizes e deveres para o Governo e que dá lugar a responsabilidades políticas e jurídicas ${ }^{6}$.
\end{abstract}

\subsection{Princípios, diretrizes e objetivos}

Como visto, o Plano Diretor é o instrumento básico de execução da política urbana, e que deve se adequar aos princípios já estabelecidos no sistema jurídico vigente.

CÂMARA, 2003. p. 311

ALVES, Alaor Caffé. Planejamento metropolitano e autonomia municipal no direito brasileiro. São Paulo: Bushatsky, 1981. APUD MUKAI, Toshio. Direito urbano-ambiental brasileiro. São Paulo: Dialética, 2002. 
Esta é a idéia de "interpretação conforme a Constituição" propugnada por Hesse, citado por Leal ${ }^{7}$ em que toda norma jurídica deve ser criada, analisada e interpretada em consonância com o espírito da Constituição, que fixou os valores fundamentais da sociedade.

O planejamento urbano deve então obedecer aos princípios constitucionais da dignidade da pessoa humana, inclusive garantindo-lhe o direito à moradia, a função social e o direito de propriedade, o meio ambiente ecologicamente equilibrado etc.

Os princípios que devem nortear a política urbana, segundo Leal ${ }^{8}$, são apontados no "Tratado sobre cidades, vilas e povoados sustentáveis" elaborados durante a ECO-92 ${ }^{9}$ :

a) direito à cidadania, ou seja, a participação dos habitantes das cidades na condução de seus destinos; b) gestão democrática da cidade, esta compreendida como submissão do planejamento do espaço urbano ao controle e participação da sociedade civil e c) função social da cidade e da propriedade.

\subsection{Elaboração do Plano Diretor}

\subsubsection{Iniciativa}

Não dispõe a Constituição quanto à sua iniciativa, o que vem gerando alguma divergência doutrinária.

A doutrina majoritária e também a jurisprudência entendem que a competência para propor a lei que institua o Plano Diretor é do Prefeito ${ }^{10}$.

A justificativa se baseia, principalmente, no texto do art. $182, \S 10$ :

Art. $182-[\ldots]$

§ 1ㅇ - O Plano Diretor, aprovado pela Câmara Municipal, [...] (grifo nosso)

Ademais, alega-se que o Plano Diretor, como já visto, é precedido de um planejamento técnico, com estudo em diversos campos do conhecimento, e esta tarefa

7 HESSE, Konrad. Constituición y derecho constitucional. In Manual de derecho constitucional. Madrid: Marcial Pons, 2000. Apud LEAL, Rogério Gesta. Direito urbanístico: condições e possibilidades da constituição do espaço urbano. Rio de Janeiro: Renovar, 2003. p. 153

8 LEAL, 2003. p. 164.

9 CONFERÊNCIA DAS NAÇÕES UNIDAS PARA O MEIO AMBIENTE E DESENVOLVIMENTO. 1992, Rio de Janeiro. "Tratado sobre cidades, vilas e povoados sustentáveis".

10 Neste sentido: MUKAI, op. cit.; CRETELLA JR., José. Comentários à Constituição de 1988. Rio de Janeiro: Forense, 1991. 


\section{Algumas considerações sobre o Plano Diretor dos municípios e sua importância no processo de construção da cidadania e da democracia}

deveria ser conferida aos órgãos técnicos da Prefeitura. Desses órgãos não disporiam o Legislativo, pelo que estaria impedido de iniciar o processo. Ressalte-se ainda, que o Poder Executivo já disporia de dados catalogados referentes ao planejamento.

Numa outra linha de raciocínio posicionam-se doutrinadores que alargam a prerrogativa de iniciativa da lei ao Poder Legislativo, além do Poder Executivo, através do Prefeito ${ }^{11}$.

Essa corrente não discute a competência do Prefeito para propor a lei instituidora do Plano Diretor. Com efeito, é a função administrativa do Estado que tem o dever precípuo de colocar em prática serviços públicos e atividades administrativas com o escopo de alcançar os comandos constitucionais e legais.

A questão que surge decorre de eventual inércia do Prefeito em propor a lei.

Deverá então toda a coletividade se privar de um importantíssimo instrumento jurídico na busca de um dos princípios constitucionais?

Cristina Fortini ${ }^{12}$ aponta alguns elementos que entende justificadores da competência do Poder Legislativo em propor a lei instituidora do Plano Diretor, em caso de omissão do Prefeito.

O argumento mais importante, segundo a autora, é o da "indisponibilidade do interesse público" ${ }^{13}$. É de interesse da sociedade a elaboração de um Plano Diretor, certamente respaldado por amplo debate popular, tema que se abordará adiante.

\subsubsection{A participação popular}

O processo de produção, implementação e execução de políticas públicas, se dá através da democracia representativa, com o poder sendo exercido por representantes eleitos, da democracia direta, com os membros atuando diretamente, e da democracia

11 Neste sentido: FORTINI, Cristiana. "Plano Diretor - Temas polêmicos. Discussão sobre a iniciativa para sua elaboração. A imperiosidade de Plano Diretor para apurar o cumprimento da função social da propriedade". Revista de Direito Municipal, Belo Horizonte, ano 5, n. 11, p. 27-36, jan./mar; 2004; BASTOS, Celso Ribeiro. Comentários à Constituição do Brasil. Rio de Janeiro: Saraiva, 1998.

12 FORTINI, 2004.

13 Este termo é definido por Celso Antônio Bandeira de Mello como: "a indisponibilidade dos interesses públicos significa que, sendo interesses qualificados como próprios da coletividade - internos ao setor público -, não se encontram à livre disposição de quem quer que seja, por inapropriáveis. O próprio órgão administrativo que os representa não tem disponibilidade sobre eles, no sentido de que lhe incumbe apenas curá-los - o que é também um dever - na estrita conformidade do que predispuser a intentio legis. MELLO, Celso Antônio. Curso de Directo Administrativo. 17. ed. São Paulo: Malheiros, 2004. 
participativa, onde há uma cooperação entre os membros e os representantes, cujo modus operandi deve ser verificado pontualmente.

De forma cristalina, o artigo 1ํㅡ, parágrafo único da Constituição Federal prevê a participação direta do povo, conjuntamente com seus representantes eleitos:

Art. 1 으 - [...]

Parágrafo único - Todo o poder emana do povo, que o exerce por meio de representantes eleitos ou diretamente, nos termos desta Constituição.

Destaque-se ainda o contido no artigo 29, inciso XII da Carta Magna:

Art. 29 - O Município reger-se-á [...], atendidos [...] os seguintes preceitos:

XII - cooperação das associações representativas no planejamento municipal.

Desta forma, asseguradas estão as três formas de democracia mencionadas anteriormente.

A legislação infraconstitucional, subordinada aos comandos hierárquicos do sistema jurídico, também explicita de que forma se daria essa democracia participativa.

O Estatuto da Cidade, Lei no 10.257/2001, é uma norma jurídica que torna obrigatória essa participação popular. Contém inclusive um Capítulo que prevê a gestão democrática da cidade. Em diversos outros dispositivos se percebe esta intenção e afirmação do legislador:

Art. 2ㅇ - A política urbana tem por objetivo ordenar o pleno desenvolvimento das funções sociais da cidade e da propriedade urbana, mediante as seguintes diretrizes gerais:

[...]

II - gestão democrática por meio de participação da população e de associações representativas dos vários segmentos da comunidade na formulação, execução e acompanhamento de planos, programas e projetos de desenvolvimento urbano;

$[\ldots]$

XIII - audiência do Poder Público Municipal e da população interessada no processo de implantação de empreendimentos ou atividades com efeitos potencialmente negativos sobre o meio ambiente natural ou construído, o conforto ou a segurança da população.

[...]

Art. 4ㅇ - Para os fins desta Lei, serão utilizados, entre outros instrumentos:

[...]

$\mathrm{V}$ - institutos jurídicos e políticos:

[...]

s) referendo popular e plebiscito; 


\section{Algumas considerações sobre o Plano Diretor dos municípios e sua importância no processo de construção da cidadania e da democracia}

Em relação ao Plano Diretor, esta obrigação da participação popular se vê mais nítida:

Art. 40 - o plano diretor, aprovado por lei municipal, é o instrumento básico da política de desenvolvimento e expansão urbana.

[...]

§ 4 - No processo de elaboração do plano diretor e na fiscalização de sua implementação, os Poderes Legislativo e Executivo Municipais garantirão:

I - a promoção de audiências públicas e debates com a participação da população e de associações representativas dos vários segmentos da comunidade;

II - a publicidade quanto aos documentos e informações produzidos;

III - o acesso de qualquer interessado aos documentos e informações produzidos.

E mais, previu ainda o Estatuto da Cidade em seu artigo 52, inciso VI:

Art. 52 - Sem prejuízo da punição de outros agentes públicos envolvidos e da aplicação de outra sanções cabíveis, o prefeito incorre em improbidade administrativa, nos termos da Lei no 8.429, de 2 de junho de 1992, quando: [...]

$\mathrm{VI}$ - impedir ou deixar de garantir os requisitos contidos nos incisos I a III do $\S 4$ 으 do art. 40 desta Lei;

Mesmo antes do advento do Estatuto da Cidade, Carneiro ${ }^{14}$ já advertia para a inconstitucionalidade do Plano Diretor sem a "cooperação das associações representativas no planejamento municipal".

Essa imposição da participação popular em vários momentos do Estatuto da Cidade, em especial na elaboração do Plano Diretor rompe uma tradição excludente das diversas camadas da sociedade, o que fortalece a legitimidade e validade desta lei municipal que regula o espaço urbano.

Com efeito, o artigo 52, VI do Estatuto da Cidade classifica como improbidade administrativa do Prefeito a atitude que possa impedir ou deixar de garantir os requisitos contidos nos incisos I a III do $\S 4$ do artigo 40 do Estatuto da Cidade.

Não só impede que o Prefeito obstaculize a participação, como impõe-lhe o ônus de colocar em prática de forma efetiva os mecanismos de participação popular.

Deve então o Prefeito adotar obrigatoriamente algumas condutas, como por exemplo: 1) divulgar da forma mais ampla possível o processo de discussão; 2) esclarecer à

14 CARNEIRO, Ruy de Jesus Marçal. Organização da cidade: planejamento municipal, plano diretor, urbanificação. São Paulo: Max Limonad, 1998. p. 111. 
população o tema abordado; 3) proporcionar meios físicos (salas, luz, horário adequado) para o debate; 4) divulgar comentários e sugestões; 5) apresentar respostas à estes comentários e sugestões.

Comentando sobre a questão dos conselhos comunitários na gestão democrática da cidade, Bucci ${ }^{15}$ faz relevante observação que se aplica à questão da participação popular no Plano Diretor:

É importante ainda que o conselho tenha meios efetivos para funcionamento, tanto no que diz respeito à dotação orçamentária própria quanto no que tange ao suporte técnico para o exercício das funções próprias.

E continua a autora ${ }^{16}$ fazendo um alerta sobre os problemas que ocorrem no Brasil quanto à falta de infra-estrutura para os conselhos, acrescentando ainda:

Isso sem falar em problemas de índole mais política, entre eles o chamado 'elitismo popular', em que se verifica uma certa especialização dos representantes da função, restando pouco espaço para o cidadão não engajado em qualquer ONG, ou ainda, a superposição de representações, como indicou uma pesquisa do Instituto Brasileiro de Administração Municipal (IBAM), que apontava os secretários de saúde e as primeiras-damas dos Municípios como integrantes de quase todos os conselhos das pequenas cidades, independentemente da área temática.

Dentro deste contexto, a doutrina vem classificando de inócuo o veto presidencial ao $\S 5^{\circ}$ do artigo 40 do Estatuto da Cidade. Assim dispunha o dispositivo vetado:

$\S 5^{\circ}$ - É nula a lei que instituir o plano diretor em desacordo com o disposto no $\S$ $4^{\circ}$.

Mukai ${ }^{17}$ classifica de inócuo o veto presidencial., segundo o que dispõe que o§ $4^{\circ}$ do artigo 40, que impõe a participação popular:

obtém sua legitimidade no próprio texto constitucional, mais precisamente no art. $1^{\circ}$, seu parágrafo único da Constituição Federal, no inciso XII do art. 29 da Constituição Federal e o direito de petição inscrito no art. $5^{\circ}$, incisos XXXIII e XXXIV da Constituição Federal.

15 BUCCI, Maria Paula Dallari. Gestão democrática da cidade. In DALLARI, Adilson Abreu; FERRAZ, Sérgio. Estatuto da Cidade: comentários à lei federal 10.257/2001. São Paulo: Malheiros, 2003. p. 330 Idem

17 MUKAI, 2002. p. 255. 


\section{Algumas considerações sobre o Plano Diretor dos municípios e sua importância no processo de construção da cidadania e da democracia}

O que se verifica nos dias atuais é que a cooperação das associações representativas no planejamento municipal "é uma espécie de vinculação imposta pelo texto constitucional” ${ }^{18}$.

Sobre o veto presidencial do $\S 5^{\circ}$ do artigo 40 , assim se posiciona Leal ${ }^{19}$ :

De qualquer sorte, é possível deduzir que, teleologicamente, a intenção veiculada pela norma não trata de facultatividade do poderes instituídos em propiciar espaços efetivos de participação comunitária no processo de constituição, fiscalização e execução do plano diretor, mas obrigatoriedade, até para ir ao encontro de todo conjunto orgânico do texto, que trabalha com a lógica da gestão compartilhada do espaço urbano com seus habitantes.

\subsubsection{Rito procedimental}

Conforme verificado, o Plano Diretor é uma lei municipal e que portanto necessita passar pelo processo legislativo. A questão da competência para elaborar o projeto de lei já foi abordada anteriormente, cabendo fazer algumas considerações sobre o rito procedimental para sua aprovação.

Nesse contexto, deve ser inserida a idéia de participação popular, de forma a se verificar como essa participação alcançará mais eficazmente seus reais objetivos, que é o engajamento da sociedade na elaboração e condução das políticas públicas, e em especial, da política urbana.

Inexistindo previsão expressa da Constituição, pode-se dizer que em relação ao quorum necessário para sua aprovação será a Lei Orgânica do Município que irá determinar.

Quanto à participação popular, é desejável que ela ocorra efetivamente com todas as conseqüências vantajosas para o desenvolvimento e equilíbrio do Município como um todo.

No entanto, como observa Oliveira ${ }^{20}$, "não há como obrigar a participação" da sociedade. O que há é um dever do Poder Público em incentivar e potencializar essa participação, inclusive é o que prevê o artigo 52, VI do Estatuto da Cidade que define como improbidade administrativa do Prefeito "deixar de garantir" a participação popular conforme previsto nos incisos I, II e III do artigo 40 da referida Lei.

CARNEIRO, 1998.

19 LEAL, 2003. p. 104 e 105.

20 OLIVEIRA, Regis Fernandes de. Comentários ao estatuto da cidade. São Paulo: Revista dos Tribunais, 2002. p. 23. 
Mukai alerta para a necessidade de um disciplinamento no modus operandi da participação popular de forma a evitar tumultos e discussões "etéreas, eternizantes e inócuas". Segundo o autor não há necessidade de lei formal disciplinando esse procedimento, bastando um ato administrativo ${ }^{21}$, em cumprimento aos comandos constitucionais e legais ${ }^{22}$.

\subsection{Conteúdo}

Seguindo a orientação contida no artigo 182 da Constituição Federal o Estatuto estabelece o conteúdo mínimo do Plano Diretor em seu artigo 42. Além desses requisitos mínimos, a doutrina vem apontando situações relevantes que devem ser abordadas pelo Plano Diretor.

Uma vez que o Plano Diretor é fruto de um prévio planejamento urbano, ele deve ser um reflexo dos estudos preliminares realizados e conter os planos de ação e instrumentos de intervenção vislumbrados, bem como orientar o desenvolvimento futuro.

Seu conteúdo cuidará, portanto, da fixação dos objetivos e diretrizes básicas.

E ainda, segundo Silva ${ }^{23}$ :

Estabelecerá as normas ordenadoras e disciplinadoras pertinentes ao planejamento territorial. Definirá sobre a ordenação do solo, estabelecendo as regras fundamentais do uso do solo, incluindo o parcelamento, o zoneamento, o sistema de circulação, enfim sobre aqueles três elementos antes indicados: Sistema viário, Sistema de Zoneamento e Sistema de Lazer e Recreação.

O Plano Diretor deverá ainda ser complementado por outros instrumentos jurídicos específicos como leis de zoneamento, posturas, proteção ambiental etc.

É papel do Plano Diretor balizar as duas vias de concretização do urbanismo que são: a) as regulamentações edilícias e b) a ordenação física e social da cidade.

21 Definição de ato administrativo: "declaração do Estado (ou de quem lhe faça as vezes - como, por exemplo, um concessionário de serviço público), no exercício de prerrogativas públicas, manifestada mediante providências jurídicas complementares da lei a título de lhe dar cumprimento, e sujeitas a controle de legitimidade por órgão jurisdicional”. MELLO, 2004.

22 Em posição contrária Regis Fernandes de Oliveira entende que "a lei municipal é que vai estabelecer como será a participação democrática da população, diretamente ou por suas entidades representativas". OLIVEIRA, 2002.

23 SLVA, 1995. p. 133. 


\section{Algumas considerações sobre o Plano Diretor dos municípios e sua importância no processo de construção da cidadania e da democracia}

Em relação à área de abrangência o Estatuto da Cidade dispõe expressamente que o Plano Diretor deverá englobar o território do município como um todo (artigo 40, § $2^{\circ}$ ).

A doutrina diverge quanto à aplicabilidade deste dispositivo no que tange à disposições sobre a área rural no Plano Diretor.

A questão que se coloca refere-se à competência privativa da União para legislar sobre direito agrário, nos termos do art. 22, I da Constituição Federal:

Art. 22 - Compete privativamente à União legislar sobre:

I - direito civil, comercial, penal, processual, eleitoral, agrário, marítimo, aeronáutico, espacial e do trabalho.

O tema merece uma reflexão baseada na teoria da interpretação conforme a Constituição defendida por Konrad Hesse ${ }^{24}$.

O estudo do Estatuto da Cidade e do Plano Diretor se baseia na idéia de cidades como espaços urbanos.

Conforme observado por Carneiro ${ }^{25}$, o conceito de cidade é diferente de município. Citando Robert Ezra Park pode-se então dizer que "a cidade não é meramente um mecanismo físico e uma construção artificial. Está envolvida nos processos vitais das pessoas que a compõem; é um produto da natureza, e particularmente da natureza humana".

No entanto, a cidade está inserida no município, devendo o Plano Diretor das cidades fazer parte do planejamento integral do município. É neste contexto que deve se basear o Plano Diretor, como inclusive está disposto no art. $40, \S 1^{\circ}$ do Estatuto da Cidade.

A atuação do legislador municipal deve se ater aos aspectos urbanísticos.

São exemplos dessa atuação: a) forma de expansão urbana; b) uso de áreas rurais importantes ao desenvolvimento urbano em virtude de recursos ambientais ou hídricos; c) trânsito de veículos automotores entre cidades e centros urbanos etc.

\subsection{Obrigatoriedade}

A Constituição Federal, em seu artigo 182 determina que o Plano Diretor é obrigatório para cidades com mais de vinte mil habitantes.

\footnotetext{
24 HESSE APUD LEAL, 2003.

25 CARNEIRO, 1998. p 114-115.
} 
O Estatuto da Cidade, em seu artigo 41, incisos II a V, alargou essa obrigatoriedade para cidades: a) integrantes de regiões metropolitanas e aglomerações urbanas; b) onde o Poder Público municipal pretenda utilizar os instrumentos previstos no $\S 4^{\circ}$ do artigo 182 da Constituição Federal; c) integrantes de áreas de especial interesse turístico; d) inseridas na área de influência de empreendimentos ou atividades com significativo impacto ambiental de âmbito regional ou nacional.

A doutrina diverge quanto à constitucionalidade deste dispositivo legal.

Mukai $^{26}$ entende que o inciso II do artigo 41 do Estatuto da Cidade é inconstitucional.

Ao prever a obrigatoriedade para cidades integrantes de área de especial interesse turístico, falta-lhe respaldo constitucional, uma vez que as outras hipóteses se encaixam em diversos dispositivos da Constituição Federal de 1988.

Por sua vez, Fiorillo ${ }^{27}$ afirma que todos os dispositivos do Estatuto da Cidade que impõem a obrigação de instituir o Plano Diretor além da hipótese constitucional de cidades com mais de vinte mil habitantes também são inconstitucionais. Cita inclusive o referido autor uma decisão do Egrégio Supremo Tribunal Federal que declarou inconstitucional dispositivo da Constituição Estadual do Amapá que exigia elaboração de Plano Diretor para os municípios com mais de cinco mil habitantes.

Em sentido contrário, ou seja, entendendo que o artigo 41 do Estatuto da Cidade não incorre em vício de inconstitucionalidade, se posiciona Câmara ${ }^{28}$.

O referido autor analisa primeiramente a possibilidade de somente a Constituição poder obrigar Entes da Federação a editar os Planos Diretores, não podendo uma lei federal, no caso o Estatuto da Cidade, alargar aquele rol de obrigados, o que geraria a inconstitucionalidade dos incisos II, IV e V do artigo 41.

Mais uma vez, valendo-se da idéia da interpretação conforme a Constituição, defende o autor que a disciplina constitucional de competência em matéria urbanística comporta o novo comando do Estatuto da Cidade. Cabe à União editar normas gerais sobre

MUKAI, 2002. p. 256-257.

27 FIORILLO, Celso Antonio Pacheco. Estatuto da cidade comentado: Lei 10.257/2001: lei do meio ambiente artificial. São Paulo: Revista dos Tribunais, 2002. p. 257.

28 CÂMARA APUD DALLARI \& FERRAZ, 2003. p. 313. 


\section{Algumas considerações sobre o Plano Diretor dos municípios e sua importância no processo de construção da cidadania e da democracia}

o assunto, e assim o fez o Estatuto da Cidade que inclusive define algumas características jurídicas de novos institutos, como por exemplo, a outorga onerosa do direito de construir.

Seria, portanto, plenamente cabível instituir, como norma geral, e seguindo as diretrizes do próprio Estatuto da Cidade, novas hipóteses de obrigatoriedade de elaboração do Plano Diretor.

A previsão constitucional seria apenas um limite mínimo a ser seguido, não podendo ser contrariado.

Também neste sentido se posiciona Fortini ${ }^{29}$, para quem a Constituição Federal "não encerra em si a competência para dispor sobre política urbana, remetendo à lei federal, nos termos do caput do artigo 182, o tratamento adicional da matéria, sem prejuízo, obviamente, da competência municipal".

\subsection{Controle de constitucionalidade e responsabilidades}

No que tange ao controle de constitucionalidade do Plano Diretor, deve-se analisar o sistema constitucional acerca da questão.

Existe a ação direta e a via de exceção. Uma vez que o Plano Diretor é uma lei municipal, o artigo 102, I da Constituição Federal veda o controle concentrado, mas que poderá se operar por via do recurso extraordinário (art. 102, III, Constituição Federal).

Vislumbra-se ainda no texto constitucional a possibilidade da intervenção do Estado em seus municípios, de forma a assegurar a observância dos princípios indicados na Constituição Estadual (artigo 35, IV, Constituição Federal):

Art. 35 - O Estado não intervirá em seus Municípios, nem a União nos Municípios localizados em Território Federal, exceto quando:

[...]

IV - o Tribunal de Justiça der provimento a representação para assegurar a observância de princípios indicados na Constituição Estadual, ou para prover a execução de lei, de ordem ou de decisão judicial.

Há ainda a possibilidade do Poder Judiciário estadual exercer esse controle de constitucionalidade de ato normativo municipal em face da Constituição Estadual.

29 FORTINI, 2004. p. 30. 
Uma outra possibilidade de controle de constitucionalidade observado por Leal $^{30}$, se dá no caso de inércia, seja do Legislativo como do Executivo.

A Constituição Federal prevê em seu artigo 103 a ação de inconstitucionalidade por omissão. Segundo o autor este preceito deve ser aplicado nos casos de omissão da Câmara dos Vereadores ou do Executivo Municipal:

Art. 103 - Podem propor a ação direta de inconstitucionalidade e a ação declaratória de constitucionalidade:

$[\ldots]$.

§ 2 ㅇ - Declarada a inconstitucionalidade por omissão de medida para tornar efetiva norma constitucional, será dada ciência ao Poder competente para a adoção das providências necessárias e, em se tratando de órgão administrativo, para fazê-lo em trinta dias.

Ainda em relação à matéria, prevê a Constituição Federal em seu artigo $5^{\circ}$, LXXI, a utilização do mandando de injunção "sempre que a falta de norma regulamentadora torne inviável o exercício dos direitos e liberdades constitucionais e das prerrogativas inerentes à nacionalidade, à soberania e à cidadania".

No que se refere ao processo de elaboração do Plano Diretor, há a necessidade de efetiva participação popular na sua confecção, execução e fiscalização, que representam verdadeiro direito e exercício da cidadania, cabendo então o mandado de injunção.

Também é cabível esta ação constitucional no caso de não elaboração do Plano Diretor, que se constitui verdadeiro instrumento do exercício dos direitos e liberdades constitucionais, citando apenas como exemplo o direito à moradia (art. $6^{\circ}$, caput, Constituição Federal), ao meio ambiente ecologicamente equilibrado (art. 225, caput) e ao bem-estar dos habitantes da cidade em função da política de desenvolvimento urbano e do Plano Diretor (art. 182 , caput e $\S 1^{\circ}$ ):

Art. $6^{\circ}$ - São direitos sociais a educação, a saúde, o trabalho, a moradia, o lazer, a segurança, a previdência social, a proteção à maternidade e à infância, a assistência aos desamparados, na forma desta Constituição.

Art. 225 - Todos têm direito ao meio ambiente ecologicamente equilibrado, bem de uso comum do povo e essencial à sadia qualidade de vida, impondo-se ao Poder Público e à coletividade o dever de defendê-lo e preservá-lo para as presentes e futuras gerações

Art. 182 - A política de desenvolvimento urbano, executada pelo Poder Público municipal, conforme diretrizes gerais fixadas em lei, tem por objetivo ordenar o

30 LEAL, 2003. p. 173. 


\section{Algumas considerações sobre o Plano Diretor dos municípios e sua importância no processo de \\ construção da cidadania e da democracia}

pleno desenvolvimento das funções sociais da cidade e garantir o bem-estar de seus habitantes.

$\S 1^{\circ}$ - O plano diretor, aprovado pela Câmara Municipal, obrigatório para cidades com mais de vinte mil habitantes, é o instrumento básico da política de desenvolvimento e de expansão urbana.

Segundo Barroso ${ }^{31}$, o Judiciário ao julgar o mandado de injunção deve suprir a "falta de regulamentação, criando a norma para o caso concreto, com efeitos limitados às partes do processo".

No caso da não elaboração do Plano Diretor, a legitimação ativa do Mandado de Injunção, segundo Barroso ${ }^{32}$, não destoa da geral, cabendo aos titulares do direito cujo exercício está obstado por falta de uma norma regulamentadora, às entidades de classe ou associativas, aos sindicatos e ao Ministério Público.

Outro importante instituto jurídico de que se vale a sociedade para obter seu Plano Diretor é a Ação Civil Pública tendente a tutelar a ordem urbanística:

Art. $1^{\circ}$ - Regem-se pelas disposições desta Lei, sem prejuízo da ação popular, as ações de responsabilidade por danos morais e patrimoniais causados: [...]

VII - à ordem urbanística.

Conforme observa Mukai ${ }^{33}$, não haverá ingerência do Poder Judiciário no Poder Legislativo Municipal ao obrigá-lo a editar o Plano Diretor. Deve-se levar em consideração o princípio da função social da propriedade que será estabelecido com o Plano Diretor.

Há de se observar ainda que o Estatuto da Cidade prevê em seu artigo 52, VII, que o Prefeito incorrerá em improbidade administrativa, sujeito portanto aos preceitos da lei $n^{\circ}$ 8.429/92, se não tomar as providências para que o Plano Diretor seja aprovado em até cinco anos após a aprovação do Estatuto da Cidade, conforme prevê o artigo 50.

Conforme se pode observar o Plano Diretor é um dos instrumentos jurídicos mais importantes em favor da comunidade, seja na busca de uma maior interação entre seus membros, na medida em que possibilita o debate racional de idéias e propostas na sua fase de elaboração, seja na possibilidade de obter uma ocupação e utilização equilibrada do solo

\footnotetext{
31 BARROSO, Luís Roberto. O direito constitucional e a efetividade de suas normas: limites e possibilidades da Constituição brasileira. Rio de Janeiro: Renovar, 2002. p. 255

32 BARROSO, 2002. p. 255.

33 MUKAI, 2002. p. 262.
} 
urbano, fazendo com que a propriedade urbana cumpra sua função social, ou ainda num processo de solidificação da cidadania e da democracia participativa.

\section{Referências}

BANDEIRA DE MELLO, Celso Antônio. Curso de Directo Administrativo. 17. ed. São Paulo: Malheiros, 2004.

BARROSO, Luís Roberto. O direito constitucional e a efetividade de suas normas: limites e possibilidades da Constituição brasileira. Rio de Janeiro: Renovar, 2002.

BASTOS, Celso Ribeiro. Comentários à Constituição do Brasil. Rio de Janeiro: Saraiva, 1998.

BUCCI, Maria Paula Dallari. Gestão democrática da cidade. In: DALLARI, Adilson Abreu; FERRAZ, Sérgio. Estatuto da Cidade: comentários à lei federal 10.257/2001. São Paulo: Malheiros, 2003.

CARNEIRO, Ruy de Jesus Marçal. Organização da cidade: planejamento municipal, plano diretor, urbanificação. São Paulo: Max Limonad, 1998.

CRETELLA JR., José. Comentários à Constituição de 1988. Rio de Janeiro: Forense, 1991.

CONFERÊNCIA DAS NAÇÕES UNIDAS PARA O MEIO AMBIENTE E DESENVOLVIMENTO. 1992, Rio de Janeiro. "Tratado sobre cidades, vilas e povoados sustentáveis".

DALLARI, Adilson Abreu; FERRAZ, Sérgio. Estatuto da Cidade: comentários à lei federal 10.257/2001. São Paulo: Malheiros, 2003.

FIORILLO, Celso Antonio Pacheco. Estatuto da cidade comentado: Lei 10.257/2001: lei do meio ambiente artificial. São Paulo: Revista dos Tribunais, 2002.

FORTINI, Cristiana. Plano Diretor - Temas polêmicos. Discussão sobre a iniciativa para sua elaboração. A imperiosidade de Plano Diretor para apurar o cumprimento da função social da propriedade. Revista de Direito Municipal, Belo Horizonte, v. 5, n. 11, p. 27-36, jan./mar; 2004.

LEAL, Rogério Gesta. Direito urbanístico: condições e possibilidades da constituição do espaço urbano. Rio de Janeiro: Renovar, 2003.

MUKAI, Toshio. Direito urbano-ambiental brasileiro. São Paulo: Dialética, 2002. 
OLIVEIRA, Regis Fernandes de. Comentários ao estatuto da cidade. São Paulo: Revista dos Tribunais, 2002.

SILVA, José Afonso da. Direito urbanístico brasileiro. São Paulo: Malheiros, 1995. 
